\title{
Identification of the near-surface geological struc- ture and deposits for land use planning purposes in the Doubrava Region (Czech Republic)
}

\author{
${ }^{1}$ VŠB-Technical University of Ostrava, Faculty of Mining and Geology, Institute of Geological Engineering, 17 listopadu 15, 708 33, \\ Ostrava, Czech Republic \\ ${ }^{2}$ Cumhuriyet University, Faculty of Engineering, Department of Geological Engineering, 58140 Sivas, Turkey.E-mail: isik.yilmaz@gmail.com \\ iyilmaz@cumhuriyet.edu.tr; \\ ${ }^{3}$ Comenius University, Faculty of Natural Sciences, Department of Engineering Geology, Mlynská dolina, 842 15, Bratislava, Slovak \\ Republic \\ ${ }^{4}$ VŠB-Technical University of Ostrava, Faculty of Civil Engineering, Department of Building Structures, 17 listopadu 15, 708 33, Ostrava, \\ Czech Republic
}

The objective of this paper is to highlight the importance of taking engineering geological characteristics and structures into account in land use planning. There have been a number of studies worldwide dealing with this issue. However more extensive implementation into land use planning practice still remains a task for the future in many places. A case study analyzing the geological environment in relation to the sites assigned for future development according to an existing land use plan was conducted in the Doubrava Region (north-east of the Czech Republic). Here, the geological conditions have been mostly influenced by anthropogenic processes connected with black coal mining. The engineering-geological zones, the preQuaternary basement and rock workability classes in the localities where future development is proposed on land use plans were evaluated using overlay analysis in a Geographic Information System (GIS). Landscape factors were also taken into account. Significant variability was identified in the investigated geological factors that have a bearing on safe cost effective development. Use of the results in future land use planning would have considerable financial benefits in implementation of future built development and these important conditions should be used by architects and designers, builders, land use planners, developers and scientists.

\section{Introduction}

Currently, information related to the geological environment is rarely used for land use planning purposes despite the availability of a wide range of maps and informative engineering-geological reports on the subject (for instance in Willerich et al., 2009; Marschalko et al., 2012; Marschalko and Juriš, 2009; Souza et al., 2008; Brankman and Baise, 2008; Aly et al., 2005; Kiersch, 2001; Belanger and Moore, 1999; Croukamp and Rooy, 1998; Feres and Lorandi, 1998; Morfeldt and Persson, 1997; Kleb, 1997; Dai et al., 1994; Slosson, 1969). Much of this information has been used for various other purposes, including reference material, archival information prior to engineeringgeological studies and in geotechnical surveys. However more extensive implementation into land use planning practice often remains a task for the future. It is clear that the geological environment should influence a range of activities, such as decision-making processes, economic costs and land use conditions, as part of land use planning. Land use planning is a tool for people to control the development of the landscape for their own benefit and for environmental protection. Geographic information systems can be used for overlay analysis to incorporate geological environmental information into land use planning.

In the present study, engineering-geological zones with similar engineering-geological characteristics, and thus have similar conditions for foundation engineering, were defined. This step considered earthworks, estimation of potential problems with bearing capacities, relative settlement of structures in areas subject to slope movements and flood hazards in land which may contain radon hazards. The term geological environment is generalized here and findings cannot be a substitute for specialized engineering-geological surveys of development sites required for specific structures. However the information has a direct bearing on guiding future land uses and site investigations, appropriate and cost-effective design of foundations and in securing building permissions. It is unwise for investors, builders and designers to discover foundation constraints, such as unsuitable geological structures, during implementation stage resulting in higher costs and delays to development. Also scientifically valuable information concerning the quantitative and qualitative characteristics of the geological environment can be obtained from the overlay analysis.

This paper presents a case study which analyzes information on the geological environment in relation to the sites assigned for future 


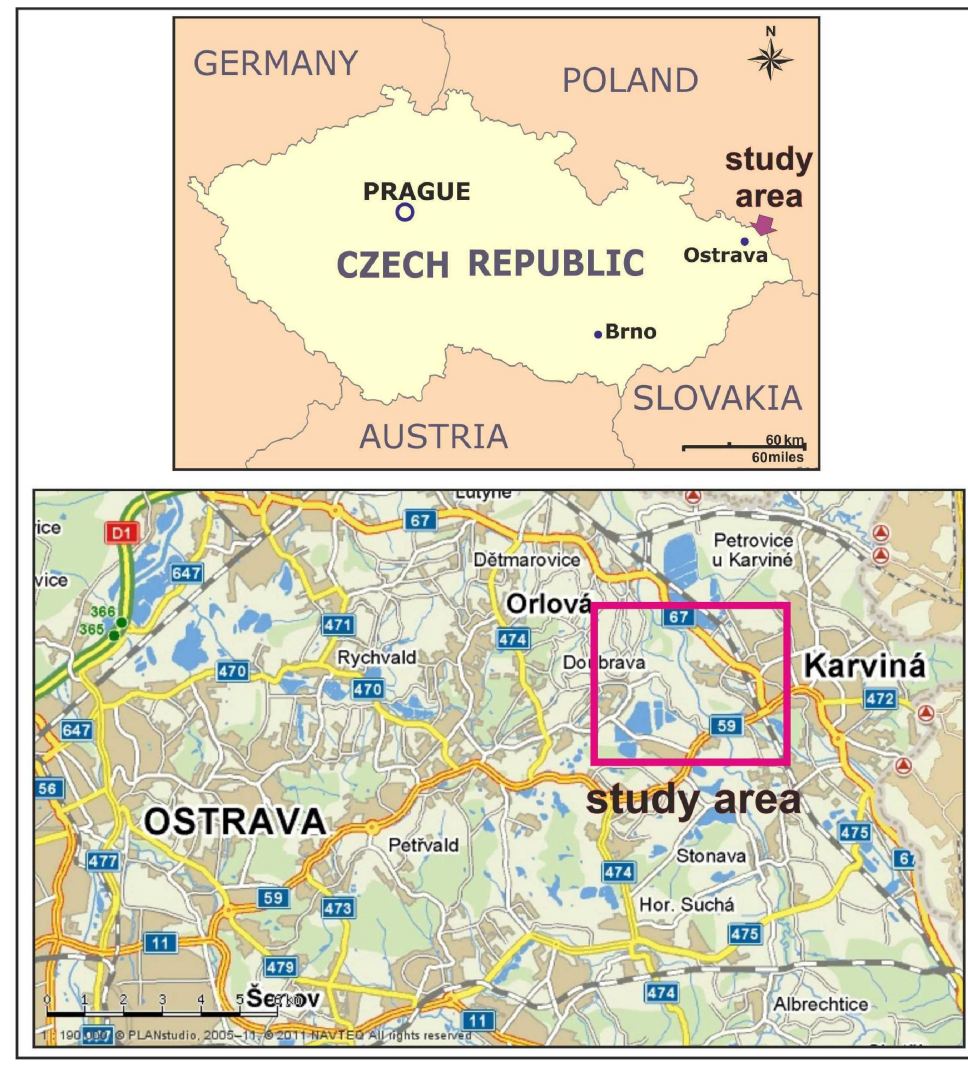

Figure 1. Location map of study area.

development according to an existing land use plan. It also particularly highlights the importance of the identification of the shallow geological deposits and structures in land use plans.

The study area lies within the municipalities of Doubrava and Karvina in the north-east of the Czech Republic (Fig. 1). This region is close to the Polish border approximately $13 \mathrm{~km}$ north-north-west of Cesky Tesin and $15 \mathrm{~km}$ east of Ostrava. The administrative centre of Doubrava is the town of Orlova. The Karvina quarter in the study area includes Doly, Frystat, Darkov Spa, Nove Mesto and Stare Mesto, as shown on map sheet 15-44-03 at a 1:10 000 scale. There are prominent mining impacts in this region caused by deep black coal mining activities in the Ostrava-Karvina Coal District (Mikulenka, 2007; Dopita and Kumpera, 1993). Mining has influenced the engineering-geological conditions, slope stability (Marschalko et al., 2008.a, b; Marschalko and Treslin, 2009) and other geodynamic processes (Kalisz, 2009).

The first part of this study focused on the engineering-geological zones. These are quasi-homogeneous land units classified according to outcropping lithologies. Initially, the overall engineering-geological conditions and characteristics were evaluated so that zones could be defined. This evaluation included the identification of the total distribution of areas in each zone in relation to the current built-up area and, most importantly, the proportion of each zone allocated for future development in the existing land use plan. These were, identified quantitatively as well as qualitatively, by comparing the geometrical distribution of the zones using overlays. The landscape elements in individual engineering-geological zones were then assessed in relation to existing development and future land use plans.

Subsequently, a study of the functional land use zones contained in the existing plan was carried out including a hierarchical examination of the distribution of the individual functional zones.
These functional zones were then studied to identify engineeringgeological zones that would influence individual building projects. The results illustrate how the geological environment is utilized in these zones and also whether there are likely to be increased costs due to the suitability, partial suitability or unsuitability of these zones for future development.

The distribution of rock workability classes was also studied with respect to the overall area, current built-up area and, more importantly, areas for future development since this will widely influence the implementation methods, costs and technology of earthworks in future development. The assessment of rock breaking characteristics and workability forms a part of engineering-geological study and it is classified in 7 rock workability classes (Table 1) based on the difficulty of their loosening and extraction under the norm of CSN 733050 Earthwork (Motlík and Hofmanová, 1987). The results were instructive and practical, and the workability of classes 1 to 4 was recognized as especially important because these are easy, and relatively inexpensive, to dig and handle. The second most important workability classes, a more expensive group from the financial point of view, was 5 to 7 . This evaluation then focused on the relationship of workability classes to the specific engineering-geological zones.

The final part of the study examined the extent and characteristics of pre-Quaternary strata at various depths in relation to the overall area, the current built-up area and areas planned for future development. This was done because: (1) understanding of the pre-Quaternary strata is vital for identifying appropriate foundation engineering technology, especially in towns which have increased population density and therefore have more built development (Marschalko et al., 2008.c); (2) Various underground transport routes or engineered services to conduct different media are constructed within these strata and, due to spatial restrictions and ease of serviceability, these cannot be located at or near the surface; (3) It is important to distinguish situations where the Quaternary strata are thin and therefore structures must automatically have their foundations in the pre-Quaternary strata; and (4) Some Quaternary strata may have difficult geotechnical properties causing problems with bearing capacity or structural settlement.

\section{Engineering-geological zones}

The principles of engineering-geological mapping are widely known and the most important output is the identification of engineering-geological zones (Yilmaz and Bagci, 2006; Tabatabaei et al., 2010; Marker, 2010; Saied et al., 2009; Yilmaz, 2009; Bednarik et al., 2010). The present study identifies eight different types of engineering-geological zone in the study area which should influence appropriate types and designs of structural foundations. It was found that the current built-up area covers $18.8 \%\left(3.4 \mathrm{~km}^{2}\right)$ of the area and the planned development, if implemented, will bring the total to $38.5 \%$ $\left(7.0 \mathrm{~km}^{2}\right)$. It is thus apparent that the built-up area is intended to be doubled in the future (Fig.2a).

The most extensive engineering-geological zone in the study area is that of alluvium of lowland and mountain streams Fn-Fh (57.7\%) (Fig.2b). This zone is composed of fine and silty-sandy fluvial clays of Holocene age. They belong to the F4 and F6 classes and, at the base, consist of sandy and sandy-clayey gravels of water courses and valley terraces. The soils are heterogeneous and have low bearing 


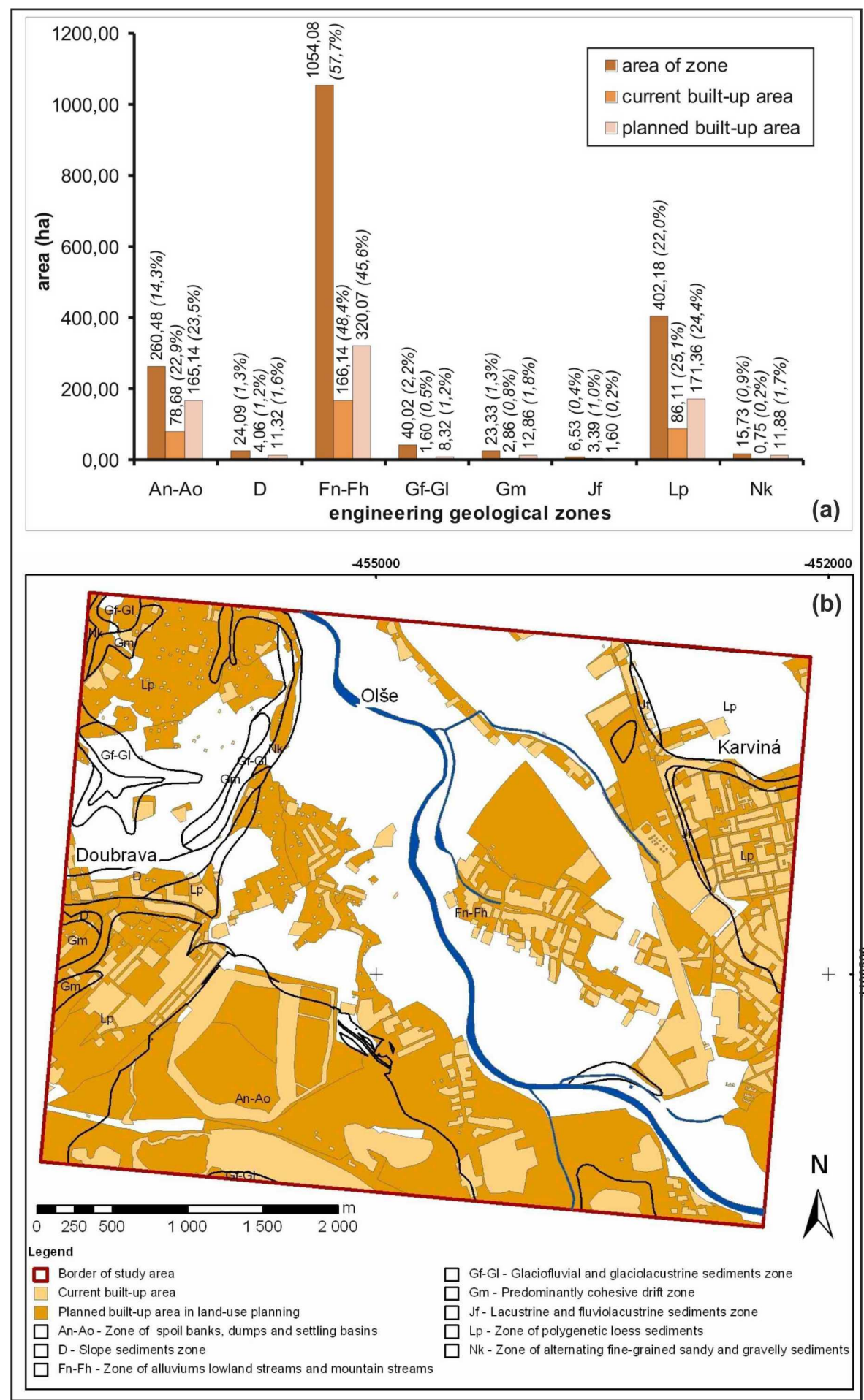

Figure 2. (a) Comparison of the total zone area with the current built-up area and future development in the studied area. (b) An overlay of the engineering-geological zones and the current built-up area and future development within the studied area.

capacity, medium to high compressibility, and relatively high porosity. Here, the ground water level is very shallow with a depth from the surface of about $0.2 \mathrm{~m}$. During determination of the total shear parameters, it was discovered that these soils are stronger if they have relatively higher proportions of silt and sand particles. The cohesion $\left(\mathrm{c}_{\mathrm{u}}\right)$ ranges from 30 to $40 \mathrm{kPa}$ and the total internal friction angle $\left(\ddot{\mathrm{o}}_{\mathrm{u}}\right)$ varies from $4^{\circ}$ to $7^{\circ}$. The workability classes are $2-3$. A high proportion of these soils include sandy clay, clay having low to medium plasticity, sand with fine-grained soil admixture, clayey sand and clayey gravel (Èurda et al, 1998).

The second most extensive zone is the zone of polygenetic loess sediments $L p(22.0 \%)$ which is concentrated in the western and north eastern parts of the region in the form of large scale loess complexes (Fig. 2b). Loess soils are observed mainly in the humid climate areas (Ostrava, Opava), or at the altitudes above 300$350 \mathrm{~m}$. They contain dust particles, but do not contain $\mathrm{CaCO}_{3}$. Wind-blown sands having the grain size between 0.1 and $0.5 \mathrm{~mm}$, mainly from the end of the last glaciation, are also preserved rarely as relics on the surfaces of the youngest terraces of major rivers. These soils have generally medium bearing capacity and compressibility, rigid to solid consistency, and they can be classified as clays with low to medium plasticity (CL, CI). Their consistency is partly rigid and partly solid. Although genuine loess has a tendency for subsidence, it can also be completely free of ground water. The sandy clay is a relatively good foundation soil and has a rock workability classification of 3 (Èurda et al., 1998).

The zone of spoil banks, dumps and settling basins zone An-Ao, at $14.3 \%$ is situated in the Karvina-Doly quarter which has been prominently affected by mining activities (Fig. 2b) in the Ostrava-Karvina Coal District. The anthropogenic deposits in this zone consist of dumps and spoil banks varying in thickness from 5 to more than $10 \mathrm{~m}$. The characteristics of these deposits negatively influence the chemistry of ground water (Èurda et al., 1998).

The other 5 zones are significantly less extensive. The glaciofluvial and glaciolacustrine sediments zone Gf-Gl (2.2\%) is situated in the north western part of the region near Doubrava (Fig. 3a). These soils are generally cohesionless and composed of sandy clay, clays having low to medium plasticity, well-grained sands and gravel, clayey sands, gravel with fine soils. Workability classes of the rocks are 2-4. In the zone of deluvial sediments $D(1.3 \%)$, observed near Doubrava, (Fig. 2b) the soils are generally clays having low to medium, high or extremely high plasticity. Workability class of the rocks is 4 . The predominantly cohesive drift zone Gm (1.3\%) outcrops in the north western part of the region in the form of layer with a width of up to $100 \mathrm{~m}$. It consists of sandy clays, clays having low to medium plasticity and gravelly clays. The workability class of rocks is $3-4$. The zone of alternating (combined) fine-grained sandy and gravelly sediments $N k(0.9 \%)$ borders the valley sides of water courses. The soils consist of sandy clays, clays with low to medium plasticity and gravelly clays. The workability class is 3-4. The lacustrine and fluviolacustrine sediments zone Jf $(0.4 \%)$ is observed in the Olse River alluvial plain in the north-eastern 


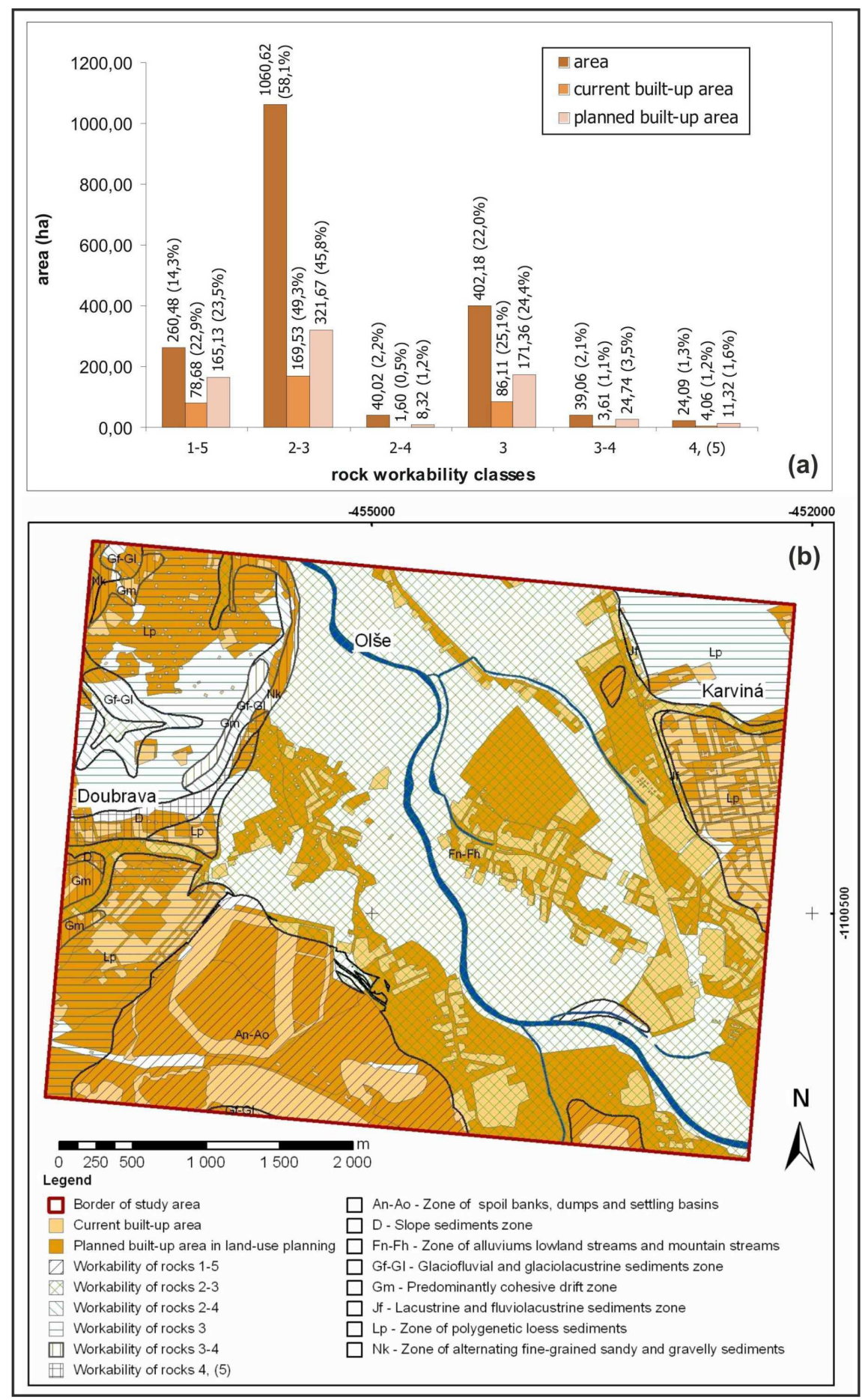

Figure 3. a. Spatial and percentage abundance of rock workability classes in relationship to the spatial extent of the studied area, the current built-up area and planned development. b. An overlay of the engineering-geological zones and rock workability classes in relation to the current and future built-up area.

part of the Karvina region (Fig. 2b) and is composed of loose and cohesive soils with frequent inter-beds of organic sediments.

\section{Workability of rocks}

The workability of rocks includes not only their breaking potential but also factors connected with loosening, loading and transport of soil, thus it is not simply determined from a laboratory or field test.
The rate of the rock workability is expressed in seven classes of workability. These reflect the amount of work necessary for the most functional methods of extraction of the rock in question, i.e. for its loosening, loading onto a vehicle and transport of the dislodged materials to the edge of the foundation pit, or to another building site (Marschalko et al., 2011). During the evaluation of the workability of rocks in the study area, it was observed that, in terms of area, the most dominant class was 2-3 which covers more than a half of the study area at $5.1 \%$ (Fig. 3a). These materials can typically be dug by spade or loader or by pickaxe and excavator (Fig. 3b). Class 2 includes fine-grained soils of soft consistency such as loam, sandy loam and sand or medium-grained gravel. Class 3 has fine-grained soils in the form of loam, loess, sandy clay, sandy and gravelly loams. Severely disrupted solid rocks, eluvia and reclaimed ground are also included in this class (Motlík and Hofmanová, 1987). These characteristics are also found in the zone of alluvium of lowland and mountain streams (FnFh) $(99.4 \%)$ which is almost wholly within this workability range, while the zone of lacustrine and fluviolacustrine sediments makes up the remaining $0.6 \%$. The latter especially predominates in the alluvial plains of the Olse and Stonavka Rivers (Fig. 3b). A high percentage (49.3\%) of the current built up area is situated on these soils and the land use plan has also reserved the largest part for future development (45.8\%). As mentioned in the section dealing with engineering-geological zones, the FnFh zone is potentially endangered by floods. Also, the physical-technical characteristics of these soils cause some foundation difficulties therefore they are less suitable of more costly for development.

Class 3 with $22.0 \%$ is the second most frequent rock workability class and it is represented by rocks of the polygenetic loess sediment zone (Lp). Although it is only conditionally suitable for development, an extensive proportion of the current built-up area is located (25.1\%), and future development of $24.4 \%$ is also planned in this zone. This class prevails in the area surrounding Doubrava and Karvina (Fig. 3a, b).

The next most important rock workability class is $1-5$ with $4.3 \%$. This is characteristic of the zone of spoil banks, dumps and settling basins (An-Ao) where sub-zones are difficult to define. However, this zone contains the widest range of workability classes from loose to solid rocks and therefore detailed high quality engineering-geological study is of utmost importance. This territory is connected with the spoils of mining in the form of made ground and frequent tailings ponds, and its character is often variable. The technical characteristics of this zone are not favourable for foundations and its deposits are not suitable for development. Nevertheless, it contains the third largest proportion of the current built-up area at $22.9 \%$ and it also has a planned development of $23.5 \%$. It is quite 
Table 1. The land use plan categorization

\begin{tabular}{|c|c|}
\hline Functional zones & Codes \\
\hline zone for land reclamation & $U_{-} F$ \\
\hline \multicolumn{2}{|l|}{ zone of individual residences } \\
\hline zone of unspecified individual residences & $U \_B I \_0$ \\
\hline zone of continuous individual residences & $U \_B I \_1$ \\
\hline zone of scattered individual residences & $U \_B I \_2$ \\
\hline zone of scattered individual residence \& garden & $U \_B I \_3$ \\
\hline zone of mixed individual residences & $U \_B I \_4$ \\
\hline mine's interest area & $U \_D L \_2$ \\
\hline \multicolumn{2}{|l|}{ production zone } \\
\hline unspecified production zone & $U_{-} V_{-} O$ \\
\hline small-scale production zone & $U_{-} V_{-} l$ \\
\hline business production zone & $U \_V \_2$ \\
\hline industrial production zone & $U \_V \_3$ \\
\hline agricultural production zone & $U_{-} V_{-} 4$ \\
\hline mixed production zone & $U_{-} V_{-} 5$ \\
\hline zone of sports and recreation & $U \_S R$ \\
\hline central zone & $U_{-} C$ \\
\hline zone of collective housing & $U_{-} B H$ \\
\hline zone of urban lawn and planting & $U_{-} U Z$ \\
\hline zone of scattered lawn and planting & $U \_Z$ \\
\hline zone of civic amenities & $U_{-} O$ \\
\hline mixed zone & $U \_S$ \\
\hline
\end{tabular}

apparent from the map overlaying the workability and development, that almost the entire area will be covered by development if the land use plan is fully implemented (Fig. 3a, b). This emphasizes the necessity of adequate knowledge of these engineering-geological zones and the character of local deposits both when considering appropriate structural foundations and in allocating land for future development.

The remaining workability classes are generally rare in this area. These are: (1) rock workability class $2-4$ at $2.2 \%$ which is characteristic in the glaciofluvial and glaciolacustrine sediments zone (Gf-Gl); (2) workability class $3-4$ at $2.1 \%$, typically in the zone of predominantly cohesive drifts $(\mathrm{Gm})$; and (3) the zone of alternating (combined) finegrained sandy and gravelly sediments (Nk). Rock workability class 4-5 has a low abundance of $1.3 \%$ and it is associated with the zone of deluvial sediments (D). Because these three workability ranges are not extensive these classes are negligible in the present study (Fig. 3a, b).

\section{Depth to pre-Quaternary deposits/ thickness of post Quaternary deposits}

Marschalko et al. (2008c) reported only one type pre-Quaternary deposit characterized by alternating cohesive and non-cohesive soils at various depths below the ground surface (Fig. 4a). This variably underlies engineering-geological zones (Fig. 4b). Pre-Quaternary bedrock with alternating solid and poorly consolidated rock units is not observed. The pre-Quaternary strata have been considered at four depth intervals: $>10 \mathrm{~m}, 5-10 \mathrm{~m},>5 \mathrm{~m}$ and $<5 \mathrm{~m}$.

At a depth $>10 \mathrm{~m}$ most of the region is characterized by alternating cohesive and non-cohesive soils $(81.8 \%)$. The most dominant of occurrences at those depths are in the zones of alluvium of lowland and mountain streams (Fn-Fh) $(46.1 \%)$; spoil banks, dumps and settling basins (An-Ao) (12.9\%); and lacustrine and fluviolacustrine sediments (Jf) $(0.4 \%)$. These three zones are generally unsuitable as

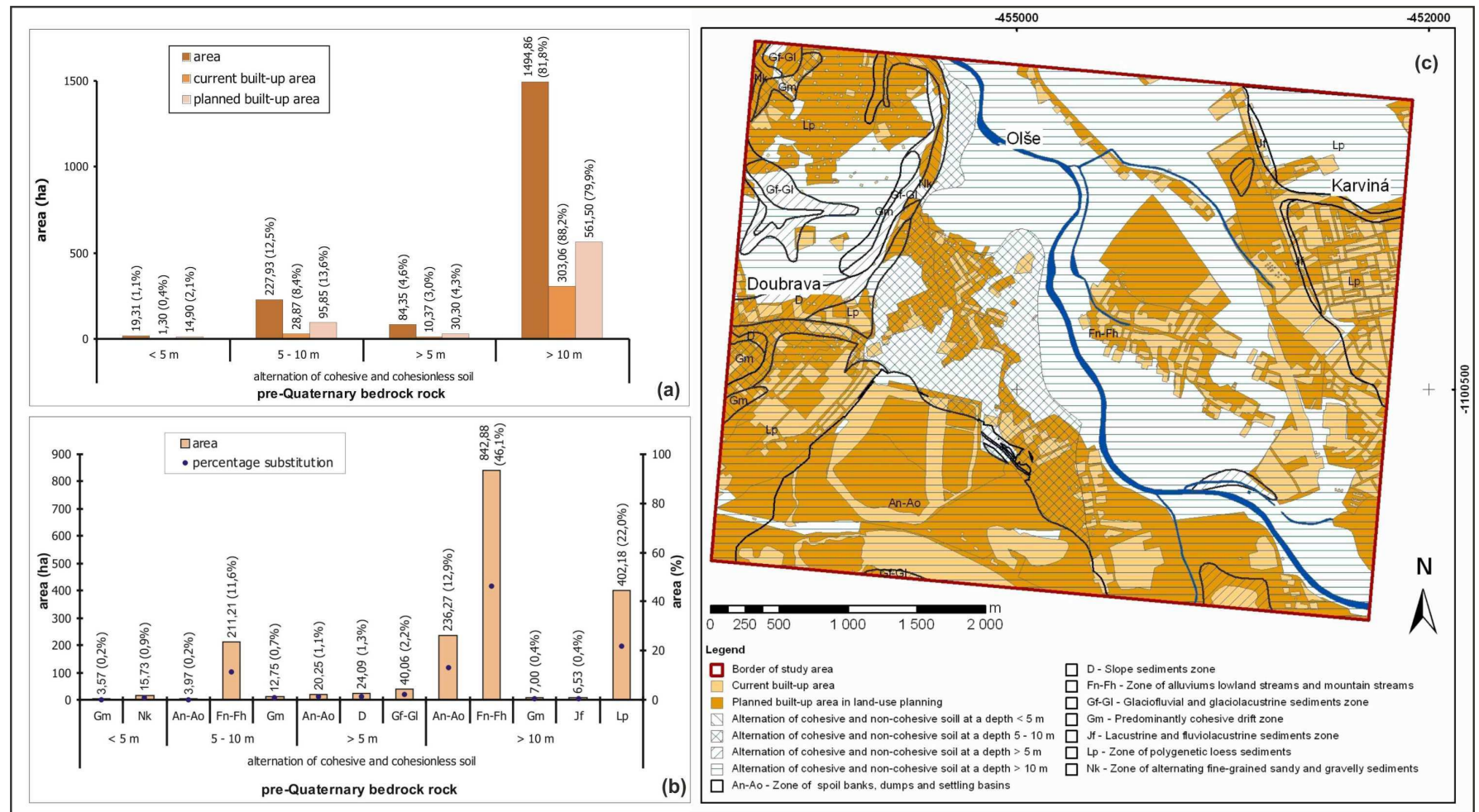

Figure 4. a. Spatial and percentage extent of the pre-Quaternary base, the current built-up area and planned development, b. Spatial and percentage extent of the pre-Quaternary base in relationship to the engineering-geological zones (for engineering-geological zone abbreviations, see Figure 4 or Table 3), c. An overlay of the engineering-geological zones and the pre-Quaternary bedrock in relationship to the current and planned built-up area. 
foundation soils thus foundations for more demanding structures should be set in the pre-Quaternary strata. However the polygenetic loess sediments (Lp) $(22.0 \%)$ and the predominantly cohesive drift zone $(\mathrm{Gm})(0.4 \%)$ are conditionally suitable for foundation engineering so the pre-Quaternary strata are there of less significance. The majority of the built-up area $(88.2 \%)$ is found on those two zones and the land use plan has its largest area allocated for future development $(79.9 \%)$ on them.

The occurrence of pre-Quaternary strata at an interval from 5-10 $m(12.5 \%)$ is associated with zones Fn-Fh $(11.6 \%), \mathrm{Gm}(0.7 \%)$ and An-Ao (0.2\%). The current built-up area covers $8.4 \%$ of this and planned development would account for $13.6 \%$. This is concentrated in the vicinity of Doubrava (Fig. 4c).

Pre-Quaternary soils with a depth $>5 \mathrm{~m}$ have a limited extent of only $4.6 \%$. They occur beneath the zones of glaciofluvial and glaciolacustrine sediments (Gf-Gl) (2.2\%) and deluvial sediments (D) $(1.3 \%)$. These areas, located near Doubrava, are conditionally suitable for construction (Fig. 4c). Spoil banks, dumps and settling basins (An-Ao) $(1.1 \%)$ are quite unsuitable for development but only a small proportion of the current built-up area is situated there (3.0\%) and planned future development $(4.3 \%)$ is not prominent.

Pre-Quaternary soils at a base depth $<5 \mathrm{~m}(11 \%)$ are least extensive and are associated with the zones of alternating (combined) fine-grained sandy and gravelly sediments $(\mathrm{Nk})(0.9 \%)$ and the predominantly cohesive drift zone $(\mathrm{Gm})(0.2 \%)$. This small surface area provides little space for building with only $0.4 \%$ of the developed area and $21 \%$ of the area planned for development.

\section{Landscape elements of engineering geological zones in the study area}

The three main engineering geological zones in the study area are those of: alluvium of lowland and mountain streams (Fn-Fh); polygenetic loess sediments (Lp); and spoil banks, dumps and settling basins (An-Ao). These cover $94 \%$ of whole study area and can be compared with landscape elements while other zones, totalling only $6 \%$ of the area, could not be compared in this way.

The most extensive landscape elements in the zone of alluvium of lowland and mountain streams (Fn-Fh) are fields and meadows $(63.5 \%)$ which are situated in the central part of the zone (Figs. 5a, d). The built-up area (15.8\%) and forests (12.7\%) are next most extensive. These cover land especially near the Olse River and the municipality of Doubrava. Rivers and water areas (8.0\%) have the lowest spatial distribution and are mainly formed by the courses of the Olse and Stonavka rivers and water areas in the northern section of the region. It became evident that if the land use plan was fully implemented, the surface area of field and meadow landscape elements would be significantly reduced from an initial $63.5 \%$ to $36.6 \%$ of the area. The built-up area would occupy a much larger area than it does at present.

Fields and meadows again dominate the landscape elements in the zone of Polygenetic loess sediments (Lp) with $71.4 \%$, and these are concentrated in rather extensive complexes predominantly in the north eastern and north western parts of the region. The built-up area is also quite extensive (21.4\%), followed by forests at $7.2 \%$ in the west, while rivers and water areas form the least extensive landscape element, so small that it cannot be expressed as a percentage (Fig. 5b). Comparing the current distribution of landscape elements with the possible implementation of the land use plan, it is apparent that the built-up area would extend across fields and meadows, where the existing surface area at $71.4 \%$ would fall to only $33.6 \%$ (Fig. 5b). It was interesting to note that, despite the rivers and water areas landscape element a small area in the municipality of Doubrava, it had been completely absorbed by built-up areas. Here, construction and foundations must take account of factors characteristic of water areas.

The distribution of landscape elements in the zone of Spoil banks, dumps and settling basins (An-Ao) is very interesting (Fig. 5c). The most extensive rivers and water areas within these $(32.0 \%)$ are tailings ponds, not natural water bodies. The current built-up area is widespread (30.2\%), and it is located in the vicinity of these ponds. Various anthropogenic features, predominantly from mining in the Ostrava-Karvina Coal District, have a wide distribution (16.6\%). However the fields and meadow zone is rather rare (13.8\%) and forests have the smallest representation (7.4\%). In this zone, the replacement of landscape elements by built-up areas is quite apparent (Fig. 5c). Implementation of the current land use plan would ensure that the built-up area would extend over almost the entire zone (93.6\%). It is of utmost importance to consider whether development is suitable in such terrains with extensive tailings pond water areas, especially when combined with adverse anthropogenic impacts.

As mentioned earlier, the engineering geological of the zones of Gf-Gl (glaciofluvial and glaciolacustrine sediments, D (deluvial sediments), Gm (predominantly cohesive drift zone), Nk (alternation of fine-grained sandy and gravely sediments) and Jf (lacustrine and fluviolacustrine sediments) are minor landscape elements of engineering geological zones in the study area, covering only $6 \%$. The respective values of cover area of the zones Gf-Gl, D, Gm, Nk and Jf are $2.2 \%, 1.3 \%, 1.3 \%, 0.9 \%$ and $0.4 \%$. Therefore examination of the landscape elements of each of these zones is difficult and would not be very useful.

\section{Functional zone structure (land use planning)}

A total of 11 basic types of functional zones have been defined in land use plans in the studied area (Table 2, Fig. 6a, b). Only a few zones are extensive. The majority of land is defined as a zone for land reclamation $\left(U_{-} F\right)(29.6 \%)$ for specified subsequent uses. This zone is located in the southern part of the study area forming a continuous zone in the quarters of Karvina - Doly and Darkov (Fig. $6 \mathrm{~b}$ ). It is predominantly associated with the zone of spoil banks, dumps and settling basins (An-Ao) and the zone of alluvium of lowland and mountain streams (Fn-Fh). A smaller area is situated in the zones of polygenetic loess sediments (Lp) and glaciofluvial and glaciolacustrine sediments (Gf-Gl).

Table 2. The norm for standard of CSN 733050

\begin{tabular}{cl}
\hline Class & Explanations \\
\hline 1 & Use of shovel and/or loader \\
2 & Use of disconnect spade and/or loader \\
3 & Use of disconnect axe and/or excavator \\
4 & Use of disconnect wedge and/or excavator \\
5 & Use of disconnect ripper and/or heavy excavator (over $40 \mathrm{t}$ ) \\
6 & and/or explosives \\
7 & Use of disconnect heavy ripper and/or explosives \\
\hline
\end{tabular}




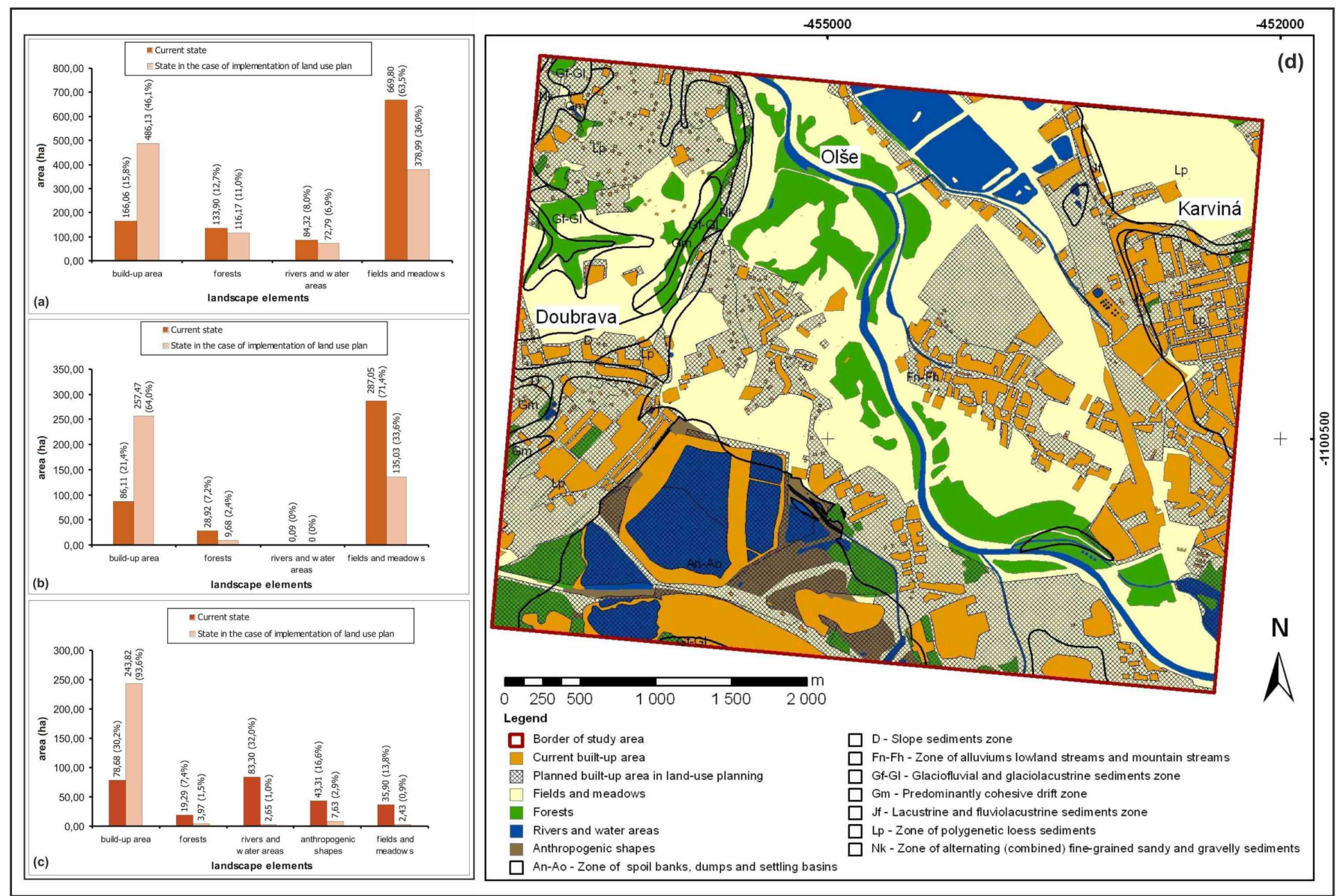

Figure 5. a. Spatial and percentage abundance of selected landscape elements at present and in the case of implementing the land use plan in the zone of a. alluviums lowland streams and mountain streams, b. polygenetic loess sediments, c. spoil banks, dumps and settling basins, $d$. An overlay of the engineering-geological zones and selected landscape elements within the studied area.

The second largest area is designated as the zone of individual residences. This covers about $20.5 \%$ of the study area and is divided into 4 sub-zones. A percentage of $9.2 \%$ is attributed to the zone of scattered individual residences $\left(U \_B I \_2\right)$, located in Doubrava in the western part of the area, and is mainly associated with the zones of Fn-Fh, Lp and in the zone of predominantly cohesive drifts $(\mathrm{Gm})$. To a lesser extent, this land use zone falls within the zones of alternating (combined) fine-grained sandy and gravelly sediments (Nk), and of deluvial sediments (D) and the zone Gf-Gl. The zone of unspecified individual residences $\left(U \_B I \_0\right)(5.9 \%)$ is limited to four quite large blocks in the eastern part of the Karvina - Mesto quarter and extends into the Fn-Fh and Lp zones. A zone of continuous individual residences $\left(U_{-} B I_{-} 1\right)(3.2 \%)$ consists of three blocks mainly in the $\mathrm{Lp}, \mathrm{Fn}-\mathrm{Fh}$ zones and to a lesser extent in the Gm zone in the surroundings of Doubrava (Fig. 6b). The zone of scattered individual residences and gardens $\left(U_{-} B I_{-} 3\right.$ ) takes up $2.2 \%$, and this is also situated near the municipality of Doubrava overlying the D, Gm, FnFh and Nk zones.

The third largest area is the production zone (19.7\%), which is divided into four sub-zones. The unspecified production zone ( $U_{-} V_{-} O$ ) (17.8\%) forms large blocks in the southern quarter of Karvina - Doly and in the eastern part of the region of Karvina - Mesto. A substantial proportion of the zone coincides with the zones of spoil banks, dumps and settling basins (An-Ao) and of alluvium of lowland and mountain streams (Fn-Fh). Much smaller areas constitute the agricultural production zone $\left(U_{-} V_{-} 4\right)(1.5 \%)$, small-scale production zone
$\left(U_{-} V_{-} 1\right)(0.2 \%)$ and the business production zone $\left(U_{-} V_{-} 2\right)(0.1 \%)$.

The mixed zone $\left(U \_S\right)$ occupies a relatively large area at $12.3 \%$. It occurs mainly in the north-western part of the region above Doubrava (Fig. 6b). Housing, business activities, sports facilities, civic amenities and lawns and planting are mixed in this zone which is mainly associated with the Lp and Fn-Fh zones.

The mines zone is limited to a specific mining interest area $\left(U_{-} D L\right)$ with $4.9 \%$. It forms one block of compact development in the south west Karvina - Doly quarter and is predominantly associated with the spoil banks, dumps and settling basins zone and partly that of the alluvium of lowland and mountain streams.

The zone of sports and recreation $\left(U_{-} S R\right)$ at $4 \%$ forms smaller polygons in various parts of the region, for example in the surroundings of Dobrava (Fig. 6b). It is mainly associated with the zone of polygenetic loess sediments but partly with the zone of alluvium of lowland and mountain streams.

Other zones also occupy small areas, such as the central zone $\left(U_{-} C\right)(2.2 \%)$, which is in the centre of Doubrava and located in the zones of D, Lp, and Fn-Fh. Next, there is the zone of urban lawn and planting (U_UZ) (2.1\%), which is in Karvina and Doubrava (Fig. $6 \mathrm{~b})$. The zone of civic amenities $\left(U_{-} O\right)(1.9 \%)$ is again concentrated in the western part of Karvina and it is related to the Lp zone. A mere $1.6 \%$ forms the zones of scattered lawn and planting $\left(U \_Z\right)$, within the northern part of Karvina, and is associated with the zones of lacustrine and fluviolacustrine sediments (Jf); alluvium of lowland and mountain streams (Fn-Fh); and polygenetic loess sediments (Lp). 


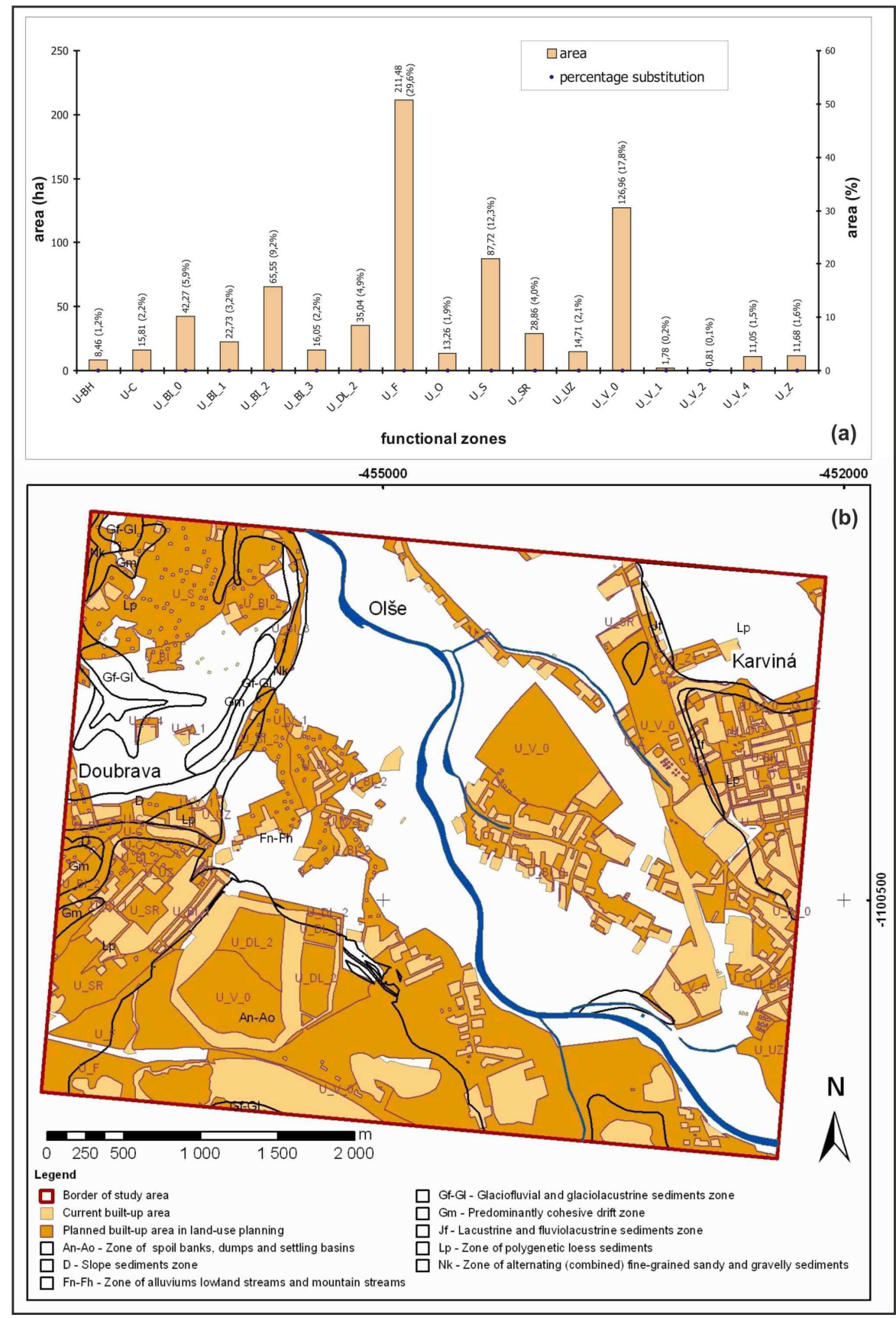

Figure 6. (a) Spatial distribution of the future development into zone types according to the land use plan within the studied area (land use plan - Regional Office, 2009), (b) An overlay of the engineering-geological zones and the future development zone types according to the land use plan within the studied area (land use plan-Regional Office, 2009).

The last and smallest land use zone is that reserved for the zone of collective housing $\left(U_{-} B H\right)(1.2 \%)$ which is situated in the northern part of Karvina and is limited to the zone of polygenetic loess sediments $(\mathrm{Lp})$.

\section{Land suitability in relation to existing and planned development}

According to its physical-technical characteristics, Fn-Fh (alluvium of lowland and mountain streams) zone is conditionally suitable for structural foundations, but flooding risk cannot be excluded. Therefore it is appropriate to re-assess the land use plans which allocate the largest portion of future development within the studied area to this zone, i.e. $45.6 \%\left(3.2 \mathrm{~km}^{2}\right)$, especially in Karvina and Doubrava. Also, the current builtup area is the most extensive in this zone within the town quarters of Karvina - Stare Mesto, Karvina - Darkov and in the municipality of Doubrava, with an area of $48.4 \%\left(1.6 \mathrm{~km}^{2}\right)$.

According technical characteristics, soils in the Lp (polygenetic loess sediments) zone can be classified as conditionally suitable for construction but deeper foundations would be needed for more demanding structures. It is essential that the land use plan should take this into account. The foundation soils in this zone include those used in the current built-up area in Karvina and Doubrava at $25.1 \%\left(0.9 \mathrm{~km}^{2}\right)$ and future development is planned there $(24.4 \%, 17$ $\mathrm{km}^{2}$ ).

The An-Ao (spoil banks, dumps and settling basins) zone is strongly influenced by mining and these anthropogenic deposits are not very suitable for foundation engineering. If structures are planned, detailed geological survey is essential and relatively high costs must be expected. Despite this, a considerable proportion of the current built-up area is in $\left(22.9 \%, 0.8 \mathrm{~km}^{2}\right)$, and much future development is planned for $\left(23.5 \%, 1.7 \mathrm{~km}^{2}\right)$, this zone linked to land reclamation.

The Gf-Gl (glaciofluvial and glaciolacustrine sediments) zone can be classified as conditionally suitable for construction therefore detailed geological survey is needed because of the inconsistent technical characteristics of the soils. This currently constitutes very small percentage or the area $(0.5 \%)$, but the land use plan for future utilization of this zone would bring this to $1.2 \%$.

Slope sediments in the $D$ (deluvial sediments) zone are only conditionally suitable for development because of their physicaltechnical characteristics. In this zone, the proportion of built-up area is $1.2 \%$, but the land use plan proposes further development of $1.6 \%$.

The Gm (predominantly cohesive drift zone) zone is conditionally suitable for foundation engineering. There is a minimal current built-up area here, at $0.8 \%$, but a more substantial area of this zone $(1.8 \%)$ is reserved for development.

However the Nk (alternating (combined) fine-grained sandy and gravely sediments) zone is not quite suitable for foundations although less demanding structures can be perhaps constructed there. Currently, a negligible proportion of built-up area $(0.2 \%)$ is observed in this zone, but the land use plan proposes more extensive utilization (1.7\%) and this will incur higher costs for implementation of foundations appropriate to conditions in the zone.

The $J f$ (lacustrine and fluviolacustrine sediments) zone has a low 
suitability for foundations but the current built-up area covers $1.0 \%$ of the whole area of this zone, and the planned development area is only $0.2 \%$ in the land use plan.

\section{Discussions and conclusions}

The results and conclusions of the present paper are as follows:

1 Upon evaluation of the engineering-geological conditions in the study area, it was discovered that the most extensive zone is that of alluvium of lowland and mountain streams $(57.7 \%$ $10.5 \mathrm{~km}^{2}$ ), which is generally unsuitable for development due to its flood risks and difficult foundation conditions. Nevertheless, the majority of the current built-up area is situated there $(48.4 \%)$ and the majority of planned development is also intended for this zone (45.6\%). It is therefore clear that the land use plan did not take into account the natural conditions of this region, and did not consider flood potential or foundation problems.

2 Examination of workability of soils demonstrated that easy-todig materials (up to class 4) dominate the study area which is a rather positive result from the point of view of future earthwork costs. The most abundant rock workability classes in the study area are classes 2-3. The extensive spread of rather low rock workability classes demonstrate the relative ease of removing such material during earthworks. Although, in some areas, builders may be exposed to relatively high costs to work classes 5 and 6, they will benefit from the cheaper costs associated with rock workability classes 6 and 7 elsewhere in the study area.

3 The pre-Quaternary bedrock contains the alternation of cohesive and cohesionless soils. The most extensive occur at depths $>10$ $\mathrm{m}$ and these are covered with Quaternary deposits, the composition of which determines the engineering-geological zonation. These especially include the zones of alluvium of lowland and mountain streams and of the spoil banks, dumps and settling basins. The majority of the current built-up area has its foundations on the soils with this pre-Quaternary $>10 \mathrm{~m}$ depth, and the land use plan also allocates most future development there (79.9\%). The least extensive areas have preQuaternary soils at shallow depth.

4 Landscape elements are predominated by fields and meadows $(58.1 \%)$, the built-up area $(18.8 \%)$ and forests concentrated along the Olse River (11.5\%). The latter consist of the landscape element of rivers and water areas $(9.2 \%)$ in the form of the Olse and Stonavka rivers and also tailings ponds. Additionally there are $2.4 \%$ of anthropogenic features in the spoil banks, dumps and settling basin zone. Consequently, it has been established that if the existing land use plan is fully implemented a significant portion of landscape elements would be displaced by the growing built-up area. Importantly, this growth would cover $96.3 \%$ of

Table 3. Engineering geological zones in the study area, and their descriptions

\begin{tabular}{|c|c|c|c|c|}
\hline Zone & Description & $\%$ & Development & Comments \\
\hline$F n-F h$ & $\begin{array}{l}\text { It is composed of fine and silty-sandy fluvial clays } \\
\text { and they are heterogeneous and low bearing capacity, } \\
\text { medium to high compressibility and relatively high } \\
\text { porosity. The values of cohesion range from } 30 \text { to } \\
40 \mathrm{kPa} \text {, and internal friction angle varies between } \\
4-7^{\circ} \text {. The workability class of rocks is } 2-3 \text {. }\end{array}$ & 57.7 & $\begin{array}{l}\text { E.D.: } 48.4 \% \\
\text { P.D.: } 45.6 \%\end{array}$ & $\begin{array}{l}\text { Conditionally suitable for structural foundation, but } \\
\text { flooding risk cannot be excluded, therefore it is } \\
\text { appropriate to re-assess the land use plan which } \\
\text { allocates the largest portion of future development } \\
\text { within the studied area to this zone. }\end{array}$ \\
\hline$L p$ & $\begin{array}{l}\text { It has medium bearing capacity, medium } \\
\text { compressibility, low to medium plasticity. The sandy } \\
\text { clay is able to form the foundation soil and the rock } \\
\text { workability class here is } 3 \text {. }\end{array}$ & 22.0 & $\begin{array}{l}\text { E.D.: } 25.1 \% \\
\text { P.D.: } 24.4 \%\end{array}$ & $\begin{array}{l}\text { Conditionally suitable for foundation engineering, } \\
\text { but it should be supported by deeper foundations } \\
\text { for more demanding structures. }\end{array}$ \\
\hline$A n-A o$ & $\begin{array}{l}\text { It is composed of anthropogenic deposits, and these } \\
\text { deposits are found in the form of spoil banks. }\end{array}$ & 14.3 & $\begin{array}{l}\text { E.D.: } 22.9 \% \\
\text { P.D.: } 23.5 \%\end{array}$ & $\begin{array}{l}\text { This zone is not suitable for development, if structures } \\
\text { are to be constructed, detailed geological survey is } \\
\text { vital and high costs must be expected. }\end{array}$ \\
\hline$G f-G l$ & $\begin{array}{l}\text { It is generally cohesionless and composed of sandy } \\
\text { clay, clays having low to medium plasticity, well- } \\
\text { grained sands and gravel, clayey sands, gravel with } \\
\text { fine soils. Workability classes of the rocks are } 2-4 \text {. }\end{array}$ & 2.2 & $\begin{array}{l}\text { E.D.: } 0.5 \% \\
\text { P.D.: } 1.2 \%\end{array}$ & It can be classified as conditionally suitable. \\
\hline$D$ & $\begin{array}{l}\text { Soils are generally clays having low to medium, high } \\
\text { and extremely high plasticity. Workability class of the } \\
\text { rocks is } 4 \text {. }\end{array}$ & 1.3 & $\begin{array}{l}\text { E.D.: } 1.2 \% \\
\text { P.D.: } 1.8 \%\end{array}$ & $\begin{array}{l}\text { The slope sediments in this zone are only conditionally } \\
\text { suitable for development. }\end{array}$ \\
\hline$G m$ & $\begin{array}{l}\text { It consists of sandy clays, clays having low to medium } \\
\text { plasticity, gravelly clays. The workability class of } \\
\text { rocks is } 3-4 \text {. }\end{array}$ & 1.3 & $\begin{array}{l}\text { E.D.: } 0.8 \% \\
\text { P.D. } 1.8 \%\end{array}$ & $\begin{array}{l}\text { This zone is conditionally suitable for foundation } \\
\text { engineering. }\end{array}$ \\
\hline$N k$ & $\begin{array}{l}\text { Soils are composed of sandy clays, clays having low to } \\
\text { medium plasticity, gravelly clays. The workability } \\
\text { class of rocks is 3-4. }\end{array}$ & 0.9 & $\begin{array}{l}\text { E.D.: } 0.2 \% \\
\text { P.D.: } 1.7 \%\end{array}$ & $\begin{array}{l}\text { This zone is not very suitable for development, or perhaps } \\
\text { less demanding structures can be constructed there. }\end{array}$ \\
\hline$J f$ & $\begin{array}{l}\text { It consists of sandy clays, and the workability class of } \\
\text { rocks is } 2-3 \text {. }\end{array}$ & 0.4 & $\begin{array}{l}\text { E.D.: } 1.0 \% \\
\text { P.D.: } 0.2 \%\end{array}$ & $\begin{array}{l}\text { This zone is classified as foundation soils in the form of } \\
\text { sandy clay and they have low suitability for foundation } \\
\text { structures. }\end{array}$ \\
\hline
\end{tabular}

Fn-Fh: alluviums lowland streams and mountain streams; Lp: polygenetic loess sediments; An-Ao: spoil banks, dumps and settling basins; Gf-Gl: glaciofluvial and glaciolacustrine sediments; D: deluvial sediments; Gm: predominantly cohesive drift zone; Nk: alternating (combined) fine-grained sandy and gravely sediments; Jf: lacustrine and fluviolacustrine sediments. E.D.: existing development area; E.D.: proposed developement area. 
the geotechnically difficult spoil banks, dumps and settling basin zone.

5 It is apparent that, the planned built-up area will involve increased development. Currently, only $3.4 \mathrm{~km}^{2}$ of the area is built over and the land use plan reserves a further $7.0 \mathrm{~km}^{2}$. Therefore complete implementation of the land use plan would ensure that $57.3 \%$ of the study area would eventually be covered by built development. Importantly, the zone of alluvium of lowland and mountain streams is not very suitable for development, and a considerable proportion of both the current and planned development is also situated in the developmentally unsuitable spoil banks, dumps and settling basin zone. Therefore, future foundation structures in such conditions must be preceded by detailed engineering-geological surveys, which will provide complete information on the nature of the physical-mechanical characteristics, the heterogeneity and the depth of anthropogenic deposits.

6 The largest area in the land use plan functional zones is allocated for land reclamation (29.6\%). This is predominantly associated with the spoil banks, dumps and settling basin zone. It is a good example of soil characteristics affected by mining activities and currently is not generally suitable for housing or recreation. In this functional zone type, it will be necessary to reclaim the land to a standard suitable for its intended future use. On the other hand, the zone of individual residences is often located in the zone of alluvium of lowland and mountain streams which is potentially endangered by floods.

These findings should be incorporated in future land use planning, and especially in building office information services, in order to facilitate higher quality decision-making, planning and the optimization of building activities. Engineering geological zones in the study area, their descriptions, suggestions and comments are summarised in Table 3 .

\section{Acknowledgement}

The authors thank the Czech Science Foundation for their support of this project (GAÈR - 105/09/1631) which forms the basis of this article. Authors are deeply grateful to an anonymous reviewer for her/his very constructive comments and suggestions which led to the improvement of the quality of the paper.

\section{References}

Aly, M.H., Giardino, J.R. and Klein, A.G., 2005, Suitability assessment for New Minia City, Egypt: A GIS approach to engineering geology. Environmental \& Engineering Geoscience, v. 11 (3), pp. 259-269.

Bednarik, M., Magulova, B., Matys, M., Marschalko, M., 2010, Landslide susceptibility assessment of the Kralovany-Liptovsky Mikulas railway case study. Physics and Chemistry of the Earth, v. 35 (3-5), pp. 162-171.

Belanger, J.R., Moore, C.W., 1999, The use and value of urban geology in Canada: A case study in the National Capital Region. Geoscience Canada, v. 26 (3), pp. 121-129.

Brankman, C.M., Baise, L.G., 2008, Liquefaction susceptibility mapping in Boston, Massachusetts. Environmental \& Engineering Geoscience, v. 14 (1), pp. 1-16.

Budetta, P., Santo, A., Vivenzio, F., 2008, Landslide hazard mapping along the coastline of the Cilento region (Italy) by means of a GIS-based parameter rating approach. 32nd International Geological Congress, AUG 20-28, 2004 Florence, Italy. Geomorphology, v. 94 (3-4), pp. 340-352
Croukamp, L., van Rooy, J.L., 1998, An engineering geological information system for land-use planning in South Africa: Results from the PretoriaJohannesburg region. Eighth International Congress International Association for Engineering Geology And The Environment, Proceedings, Vols 1-5, Vancouver, Canada, pp. 2579-2585

Èurda, J., Drábková, E., Eliáš, M., Jinochová, J., Kašpárek, M., Manová, M., Müller, V., Nováková, D., Rù•ièka, M., Šalanský, K., Tomášek, M., Veselý, J., 1998, Notes to the set of geological and ecological specialpurpose maps of natural resources in 1:50 000 scale (Sheet 15-44 Karviná). Czech Geological Institute, Prague, 89 p. ISBN 80-7075-31102 (in Czech)

Dai, Fc., Liu, Yh., Wang, Sj., 1994, Urban Geology - A Case-Study Of Tongchuan City, Shaanxi Province, China. Engineering Geology, v. 38 (1-2), pp. 165-175

Dopita, M., Kumpera, O., 1993. Geology of the Ostrava-Karvina coalfield, upper Silesian basin, Czech-republic, and its influence on mining. International Journal of Coal Geology, v. 23 (1-4), pp. 291-321

Feres, R. and Lorandi, R., 1998, Geotechnical characterization of valley floors as support to urban occupation in Rio Branco, Brazil. Eighth International Congress International Association for Engineering Geology and The Environment, Proceedings, Vols 1-5, Vancouver, Canada, pp. 2687-2692

Hearn, G.J., Massey, C.I., 2009. Engineering geology in the management of roadside slope failures: contributions to best practice from Bhutan and Ethiopia. Quarterly Journal of Engineering Geology and Hydrogeology, v. 42 , Part 4, pp. $511-528$

Kalisz, P, 2009. Impact of mining-induced surface deformations on reinforcement of structural embankments. Archives of Mining Sciences 54 (4), pp. 657-670

Kiersch, G.A., 2001, Development of engineering geology in western United States. Engineering Geology, v. 59 (1-2), pp. 1-49

Kleb, B., 1997, The role of engineering geology in the urban development and regional planning. Engineering Geology and the Environment, Vols 1-3, pp. 1299-1301

Marker, B.R., 2010. Review of approaches to mapping of hazards arising from subsidence into cavities. Bulletin of Engineering Geology and the Environment, v. 69 (2), pp. 159-183

Marschalko, M., Fuka, M. and Treslin, L., 2008a, Influence of mining activity on selected landslide in the Ostrava-Karvina coalfield. Acta Montanistica Slovaca, v. 13 (1), pp. 58-65

Marschalko, M., Fuka, M. and Treslin, L., 2008b, Measurements by the method of precise inclinometry on locality affected by mining activity. Archives of Mining Sciences, v. 53 (3), pp. 397-414

Marschalko, M., Lahuta, H. and Juris, P., 2008c, Analysis of workability of rocks and type of pre-Quaternary bedrock in the selected part of the Ostrava conurbation by means of geographic information systems. Acta Montanistica Slovaca, v. 13 (2), pp. 195-203

Marschalko, M. and Juris, P., 2009, Task of engineering geology in land-use planning on the example of four selected geofactors. Acta Montanistica Slovaca, v. 14 (4), pp. 275-283

Marschalko, M., Treslin, L., 2009, Impact of underground mining to slope deformation genesis at Doubrava Ujala. Acta Montanistica Slovaca, v. 14 (3), pp. 232-240

Marschalko, M., Bednarik, M., Yilmaz, I., 2011. Evaluation of engineeringgeological conditions for conurbation of Ostrava within GIS environment. Environmental Earth Sciences. DOI: 10.1007/s12665-012-1547-9

Marschalko, M., Yilmaz, I., Bednarik, M. and Kubecka, K., 2012, Variations in the building site categories in the underground mining region of Doubrava (Czech Republic) for land use planning. Engineering Geology, v. 122 (3-4), pp. 169-178.

Mikulenka, V., 2007, Influence of the mining works on the roads in OstravaKarvina's distrikt. Acta Montanistica Slovaca 12, Special Issue 3, pp. $465-470$

Morfeldt, D., Persson, L., 1997, Research and documentation on the importance of engineering geology in some underground projects in Stockholm. Tunnelling and Underground Space Technology, v. 12 (4), pp. $473-477$ 
Motlík, M., Hofmanová, A., 1987, Standard ÈSN 733050 Earthworks. Replaces from ÈSN 733050 August 21, 1963, effective from September 1, 1987. UNM Publishing, 36 pp. (in Czech)

Saied, P., Pradhan, B. and Amir, M., 2009, Stability Mapping and Landslide Recognition in Zagros Mountain South West Iran: A Case Study. Disaster Advances 2 (1), pp. 47-53

Slosson, J., 1969, Role of engineering geology in urban planning. TransactionsAmerican Geophysical Union 50 (11), pp. 613-614

Souza, L.A., Nogueira, F.R. and Cerri, L.E.D., 2008, Application of the geology of engineering in the reduction of urban geologic risk in Itapecerica da Serra - SP: Study of case. Rem-revista Escola de Minas, v. 61 (2), pp. 121-128

Tabatabaei, S.H., Salamat, A.S., Ghalandasrzadeh, A., Riahi, M.A., Beitollahi, A., Talebian, M., 2010, Preparation of Engineering Geological Maps of Bam City Using Geophysical and Geotechnical Approach. Journal of
Earthquake Engineering, v. 14 (4), pp. 559-577

Willerich, S, Thuro, K, Mair, V, 2009. Integration of large deep-seated, creeping mass movements in a regional hazard map - an approach to determinate its probability of occurrence. Austrian Journal of Earth Sciences, v. 102 (2), pp. 61-68

Yilmaz, I., 2009, Landslide susceptibility mapping using frequency ratio, logistic regression, artificial neural networks and their comparison: a case study from Kat landslides (Tokat-Turkey). Computers and Geosciences, v. 35 (6), pp. 1125-1138

Yilmaz, I. and Yavuzer, D., 2005. Liquefaction potentials and susceptibility mapping in the city of Yalova, Turkey. Environmental Geology, v. 47 (2), pp. 175-184.

Yilmaz, I., Bagci, A., 2006. Soil liquefaction susceptibility and hazard mapping in the residential area of Kutahya (Turkey). Environmental Geology, v. 49 (5), pp. 708-719 